\title{
ALFABETIZAÇÃO, CURRÍCULO E FORMAÇÃO COM AS CRIANÇAS: REFLEXÕES A PARTIR DO COTIDIANO DA ESCOLA
}

\author{
Carmen Sanches Sampaio ${ }^{I}$ \\ Tiago Ribeiro $^{2}$ \\ Ana Paula Venâncio ${ }^{3}$
}

Nas pesquisas curriculares, na tendência chamada de pesquisas "nos/dos/com os cotidianos", realizadas por diversos grupos (...) existe um ponto em comum: o encaminhamento articulado da práticateoriaprática - práticas que se desenvolvem com criação de pensamentos e pensamentos que se desenvolvem a partir de práticas.

De um lado, enfrentando os desafios cotidianos, em Currículo, das professoras comprometidas; de outro, a condição de ver aquilo que os modos de pensar hegemônico não nos permite ver - a criação permanente dos processos curriculares pelos praticantes de currículos.

(Regina Leite Garcia e Nilda Alves)

(...) enquanto ato de conhecimento e ato criador, o processo de alfabetização tem, no alfabetizando, o seu sujeito.

(Paulo Freire)

(...) a alfabetização é um processo discursivo: a criança aprende a ouvir, a entender o outro pela leitura; aprende a falar, a dizer o que quer pela escrita.

(Mas esse aprender significa fazer, usar, praticar, conhecer. Enquanto escreve, a criança aprende a escrever e aprende sobre a escrita).

(Ana Luiza Bustamante Smolka)

\section{INTRODUÇÃO}

Há quase duas décadas nós, autorxs ${ }^{4}$ deste texto, lemos, estudamos, pesquisamos e conversamos sobre alfabetização no exercício de experienciar com as crianças o complexo processo

\footnotetext{
${ }^{1}$ Universidade Federal do Estado do Rio de Janeiro. Pós-doutora em Educação. Professora do PPGEdu/UNIRIO e do Departamento de Didática da UNIRIO. Coordenadora da Rede de Formação Docente: Narrativas e Experiências (Rede Formad). E-mail: carmensanches.unirio@gmail.com

${ }^{2}$ Colégio de Aplicação do Instituto Nacional de Educação. Doutorando em Educação pelo PPGEdu/UNIRIO. Bolsista PDSE CAPES, 2016. Professor do Colégio de Aplicação do Instituto Nacional de Educação de Surdos. Integrante da Rede de Formação Docente: Narrativas e Experiências (Rede Formad). E-mail: trsunirio@gmail.com

${ }^{3}$ Colégio de Aplicação do Instituto Superior de Educação do Rio de Janeiro (CAP/ ISERJ). Mestre em Educação pela UNIRIO. Professora do Colégio de Aplicação do Instituto Superior de Educação do Rio de Janeiro. E-mail: anapaulavenancioafrica@gmail.com
}

${ }^{4}$ A escrita da marca de gênero com o x é uma opção cada vez mais presente em textos acadêmicos, sobretudo no campo dos estudos com os cotidianos. Essa opção busca questionar uma lógica binária segundo a qual somente dois gêneros

Teias v. 18 • n. 50 • 2017(jul./set.): Conversas sobre formação de professores, práticas e currículos 
de aprenderensinar $^{5}$ a ler e a escrever. Leituras, estudos, pesquisas e conversas tecidas com muitxs outrxs, em redes de formação docente que, neste percurso, têm nos ajudado a pensar a alfabetização longe das normativas e do passo-a-passo dos métodos, com suas famílias silábicas, palavras-chave e sentenças "simples".

Essas conversas são cada vez mais importantes e, às vezes, polêmicas, pois aprendemos, em nossa maioria, durante nosso processo formativo enquanto professorxs alfabetizadorxs, a alfabetizar tendo como referência métodos mecanicistas de alfabetização, sintéticos e/ou analíticos ${ }^{6}$, os quais esvaziam o processo alfabetizador das perguntas das crianças. Métodos que têm como centralidade letras, sílabas ou palavras e frases, baseados na cópia, na memorização e na repetição das palavras da cartilha; métodos, enfim, nos quais a aprendizagem gira em torno de "conteúdos" pré-definidos pelx produtxr das cartilhas, e as perguntas, desejos e curiosidades, tanto dxs estudantes quanto dxs professorxs, no geral, não são levados em conta.

Conforme esta perspectiva teórico-metodológica de alfabetização, relações entre o vivido pelas crianças dentro e fora da escola não são valorizadas, pois o que importa, como dissemos, é a repetição e a memorização do "ensinado" pelx professxr na sequência previamente pensada e apresentada pelos respectivos métodos ou cartilhas de alfabetização. Um dos critérios a ser seguido - o da "gradação das dificuldades" da língua - limita e, muitas vezes, impede que as crianças possam escrever e ler o que desejam e o que as interessa, desencorajando articulações e sentidos entre esse aprendizado e seus conhecimentos. Trata-se de um critério pensado por adultxs; adultxs especialistas da área da linguística, que não levam em conta modos criativos e inventivos vividos pelas crianças quando assumem o desafio de registar, por escrito, a própria língua. Mas não só isto! Critérios e sequências que tampouco são pensadas pelx professxr, uma vez que também estx é destituídx de sua condição de autxr, de produtxr de conhecimento e saber pedagógico!

são possíveis: masculino e feminino, denotando machismo e misoginia, uma vez que o masculino prevalece sobre o feminino e outras expressões de gênero são invisibilizadas.

5 A junção de termos usualmente compreendidos como dicotômicos, mas que guardam entre si relações de reciprocidade e/ou retroalimentação, é um princípio constitutivo do campo dos estudos com os cotidianos (OLIVEIRA; SGARBI, 2008) frente à binarização imposta pela episteme moderna ao nosso modo de conceber processos e ações no e do mundo. Como exemplo, sublinhamos os pares teoria/prática, saber/fazer, norte/sul, ensinar/aprender, nos quais a primeira palavra da díade costuma sobrepor-se em importância à segunda.

${ }^{6}$ Métodos de marcha sintética são os que partem das partes menores para as maiores, como a letra (método alfabético), o som da letra (fonético) ou a sílaba (silábico). Nestes, primeiro se ensina exaustivamente estas partes para, posteriormente, formarem-se palavras ou pequenas frases com as famílias silábicas estudadas. Por sua vez, os métodos de marcha analítica partem das partes maiores, como palavra (palavração), frase (sentenciação) ou pequenas histórias (historieta) para chegarem à análise das partes menores da língua. Assim, o caminho percorrido por esses métodos é inverso (MORTATTI, 2000). 
Quantas vezes, como professorxs alfabetizadorxs, solicitamos que as crianças escrevessem palavras "mais fáceis", com letras e sílabas ou grafemas e fonemas "simples", em vez de palavras pensadas por elas, articulas à sua vida cotidiana. Temíamos, conforme aprendemos, que essas palavras, as pensadas pelas crianças, possuíssem letras e sílabas "difíceis", pois, de acordo com o "critério de dificuldades" da língua (pensado pelx adultx, claro!), palavras "mais difíceis" precisavam ser deixadas para depois, para quando essas "dificuldades" (como, por exemplo, palavras escritas com "ch", “ss", "lh", “ç”, “ce”, “ci”, “cl”, “qu”, “gi” etc.) já tivessem sido ensinadas! Demoramos a nos perguntar: fácil ou difícil do ponto de vista de quem? Para quem? Para as crianças ou para xs adultxs?

Perguntas simples, mas não as fazíamos porque acreditávamos, ou melhor, aprendemos a acreditar que o método de alfabetização devia ser seguido à risca, e o erro precisava ser evitado. As crianças não podiam errar, ou melhor, eram impedidas de escrever e de ler o que desejassem porque eram compreendidas como incapazes de saber o que não fosse ensinado pelx professxr. Não podiam, sobretudo, arriscar, ousar, experimentar, brincar com os sons e letras das palavras; usar, mediadas pela dúvida e pela curiosidade, a própria língua, a língua com que pensam, sonham, se aborrecem, descobrem o mundo... A sua própria língua! Assim, a nós, professorxs, cabia a execução do pensado pelx autxr da cartilha ou pelxs especialistas e assessorxs das Secretarias de Educação, o que dá a ver uma concepção de formação e trabalho docente pautada e referenciada pela perspectiva epistemológica e teórica da "racionalidade técnica e instrumental" (SCHÖN, 1992; PÉREZ GÓMEZ, 2001).

No entanto, as crianças, enquanto outrxs potentes da formação, com suas falas, gestos e ações foram nos ajudando e provocando a desconfiar de nossas verdades e certezas, foram borrando os limites de nossas compreensões e nos empurrando na direção de novas e outras perguntas: é possível alfabetizar de outros modos? É possível tornarmo-nos autorxs de nossas próprias práticas?

Essas inquietações, pouco a pouco, nos sacolejavam. Impingiam pensar no currículo da alfabetização e na nossa própria formação. Cada vez mais, incomodava-nos a ideia de um currículo e uma prática sem criação, invenção, dúvidas e autoria docente! Nesse sentido, ler, estudar e conhecer outras perspectivas epistêmico-teóricas e metodológicas de alfabetização - a psicogênese da língua escrita (FERREIRO; TEBEROSKY, 1985) e a concepção de alfabetização como processo discursivo (SMOLKA, 2008), e de formação docente provocaram que fôssemos assumindo-nos como "professoras-pesquisadoras" (GARCIA; ALVES, 2002; ESTEBAN; ZACCUR, 2002) de nossa própria prática. Passamos, então, com as crianças em sala de aula e com diferentes professorxs e alfabetizadorxs, com xs quais trabalhávamos, conversávamos e estudávamos, a ousar, 
a arriscar, a criar e a experienciar uma prática alfabetizadora que desse vida ao defendido, há muito, por Paulo Freire (2008, p. 11-12): “a leitura de mundo precede sempre a leitura da palavra e a leitura desta implica a continuidade da leitura daquele".

Fomos vivendo, de modos singulares e coletivo, processos (com)partilhados em redes de formação docente: com outrxs professorxs, em rodas de conversa, em múltiplos espaçostempos de formação, com diferentes sujeitxs. Passamos a nos perguntar: como e o que escrevem as crianças quando podem escolher o que escrever e como escrever? Que sentidos atribuem a esse processo de aprender a ler e a escrever? Como vivem esse aprendizado? O que é comum? O que não é comum? Como se relacionam, na escola e fora dela, com a linguagem escrita?

Vivenciar esse movimento, com as crianças, provocou e tem provocado o desafio de estarmos atentxs aos seus modos, diferentes e comuns, de escrever e de ler. Modos que interrogam compreensões hegemônicas sobre a prática alfabetizadora; modos que confirmam e não confirmam hipóteses defendidas pela psicogênese da língua escrita; modos que abrem possibilidades outras de aprendizagens e de ensino da linguagem escrita... exigindo o aprendizado cotidiano de lidar com as diferenças que nos constituem e que, portanto, estão presentes em toda sala de aula.

Sendo assim, neste texto, socializamos e colocamos em discussão acontecimentos e experiências vividas com uma turma do $1^{\circ}$ ano de escolaridade dos anos iniciais do Ensino Fundamental, em uma escola pública na zona norte do Rio de Janeiro. Turma formada por um grupo de crianças com cerca de seis e sete anos de idade. Além da professora alfabetizadora, um grupo de estudantes bolsistas, todxs vinculadxs ao Programa Institucional de Bolsa de Iniciação a Docência $^{7}$, um doutorando do Programa de Pós-Educação de uma universidade pública do Rio de Janeiro e a orientadora e coordenadora do projeto convivem e acompanham esta turma desde o ano anterior, quando as crianças estavam na Educação Infantil dessa própria escola, no bojo da ação de pesquisa: Filosofia com as crianças ${ }^{8}$.

Para nós, repousar a atenção sobre tais acontecimentos e experiências torna possível colocar em questão o currículo na alfabetização: O que se ensina quando se ensina a ler e a escrever? Não

\footnotetext{
7 O Programa Institucional de Bolsa de Iniciação à Docência (PIBID), oferecido pela CAPES (Coordenação de Aperfeiçoamento de Pessoal de nível Superior) por meio das universidades brasileiras que trabalham com formação de professorxs, dedica-se à concessão de bolsas a estudantes de licenciaturas que se fixem na docência durante a sua graduação. O projeto PIBID em questão é constituído por 08 subprojetos e envolve cinco cursos de licenciaturas e 13 escolas públicas.

${ }^{8}$ Com o professor e amigo Walter Kohan, em diferentes edições do Colóquio Internacional de Filosofia e Educação e, mais especificamente, através do projeto de pesquisa e extensão: Em Caxias, a filosofia en-caixa? A escola pública aposta no pensamento, conhecemos a possibilidade de vivenciarmos, com crianças e professorxs, nas escolas, experiências coletivas de pensamento no encontro entre filosofia e infâncias. (KOHAN; OLARIETA, 2012).
} 
obstante, as reflexões aqui engendradas almejam contribuir, também, para continuarmos conversando sobre a formação dx professxr alfabetizadxr.

\section{ESTAR E TORNAR-SE PROFESSXR ALFABETIZADXR COM AS CRIANÇAS}

A ideia da formação docente como um processo compartilhado não soa estranha. Cada vez mais, na literatura pedagógica, figuram pesquisas e textos que apontam a dimensão coletivoalteritária da formação de professorxs (GARCIA, 2015). Parece quase inconteste, nas atuais pesquisas do referido campo ${ }^{9}$, a afirmativa de que a formação não é um processo solitário.

No entanto, se na quase totalidade dos trabalhos sobre a temática a ideia supracitada é recorrente, talvez caiba ainda perguntar: essx outrx potente na e da formação docente, quem é? Trata-se apenas dx adultx? É a criança um outro da formação docente? Podem as crianças serem partícipes do processo formativo dx professxr?

Nossa relação com as crianças, nossos encontros com elxs, tão marcados pela imprevisibilidade, pela surpresa, pela incerteza e pela aprendizagem mútua têm nos ensinado que, sim, as crianças são sujeitxs da formação; são outrxs que nos deslocam, nos fazem tremer diante do acontecimento, do que não sabemos explicar nem podemos prever. Se temos ouvidos para escutar e olhos para ver, as crianças estão, todo o tempo e o tempo todo, provocando-nos, convidando-nos à desaprendizagem de nossas verdades mais caras e de nossos saberes que, muitas vezes, afastam-nos das dúvidas e das perguntas e, por que não dizer, dos nossos ainda não saberes!

Estar com as crianças pensando, conversando e - por que não? - filosofando sobre questões cotidianas da vida, trazidas por elxs e por nós, professorxs e estudantes, provoca-nos a viver, neste e com este processo, ações de formação docente - sempre inacabadas e inconclusas - abertas e atentas às maneiras de ser, pensar, agir e sentir das crianças. Para nós, um espaçotempo privilegiado de formação; espaçotempo de fazer-se outrx com x outrx, de desaprender-aprender-desaprenderaprender... e, quiçá, vivermos processos de formação docente na perspectiva da experiência!

Uma dessas experiências de desaprendizagem se deu em setembro de 2016, na volta às aulas na escola onde o projeto PIBID/Filosofia com crianças é vivido. Vale lembrar que 2016 foi um ano marcado, no cenário nacional brasileiro, pelo golpe legislativo-jurídico-midiático sofrido pela então presidente eleita Dilma Vana Rousseff e pelos 54.501 .118 votos que a elegeram, novamente, presidente da república, em 2014; golpe este que impôs à população um projeto de governo

\footnotetext{
${ }^{9}$ A esse respeito, ver GT 8 - Formação de Professores - da Anped.
} 
neoliberal e antidemocrático derrotado nas urnas. A nível estadual, no Rio de Janeiro, também se deflagrou uma "crise" econômica, com a falência do estado decretada pelo governador do estado, Luiz Fernando Pezão. Subsidiado pelo Decreto, o governador, colocando em marcha uma política antiga de desmonte do público em prol da privatização de serviços e direitos básicos, como educação e saúde, vem atrasando salários, não realizando repasses de verba entre outras ações, as quais fazem com que as instituições públicas estaduais vão morrendo à mingua. Diante do quadro, em 2016, a rede à qual se vincula a escola deflagrou uma intensa luta coletiva por direitos básicos negados e, portanto, um ano de paralisações e greve de docentes e funcionárixs, motivo pelo qual as aulas só começaram, nesse ano, praticamente no mês de setembro.

Após um semestre letivo entrecortado pela greve, pelo movimento potente de ocupação nas escolas pelxs estudantes secundaristas e a realização dos Jogos Olímpicos de 2016, o semestre letivo teve início. Este longo período sem aulas provocou nas crianças uma ansiedade pelo retorno à escola. Neste contexto, o reencontro com xs amigxs da turma tornava o momento da chegada um tempo de emoções e afetos.

A volta às aulas fazia desse tempo um tempo de festa, de comemorações e alegrias. Uma nova comemoração enchia o espaçotempo da sala de aula com a chegada de cada uma das crianças. Carinho, acolhimento, atenção e alegria permeavam o reencontro. Foi nesse movimento que ouvimos a fala potente de Pérola, estudante da turma:

\section{— Tia, não vai ter roda de conversas?}

As crianças imediatamente fizeram, da pergunta de Pérola, a pergunta da turma e, sem demora, começaram a pegar as esteiras. No ritmo da euforia, começaram a fazer uma roda no chão da sala. Entre um e outro assunto, a professora as desafiou a pensar e a expressar seus desejos em relação à escola através de uma palavra. Que desejos sentiam em relação à escola?

- De falar pelos cotovelos - disse-nos Carlos André.

- Eu gosto de imaginar as coisas! - expressou-se Francine.

- Pode ser brincadeira? De pique-pega?! - perguntou Vinícius.

- Eu gosto de escrever. Eu sei escrever Alemão! - disse, eufórico, Jean.

- Eu gosto de brincar, gosto de passar batom e gosto de estudar - Luyza falou.

- Futebol! - destacou Miguel, ganhando a concordância da maioria dos meninos. 
- Eu gosto de vir pra escola! Eu gosto desta escola! Gosto dos meus amigos! -ressaltou Éricka.

- A roda de conversas é de aprender! Porque quando a gente fala vem mais pensamentos! Eu gosto da roda de conversas! Eu gosto de estudar! - elencou Pérola, em seus desejos sobre a escola.

- Eu gosto muito de conversar! Gosto de estudar também! E da escola, porque todo mundo traz brinquedo - afirmou Beatriz.

- Pensar cansa, tia! - finalizou Gabriel.

Ouvir as falas das crianças durante a roda de conversa foi gratificante. Uma palavra não! Duas, três, um montão, como dizem as crianças. Algumas, falaram mais, outras, menos; outras, ainda, ficaram mais quietas, observando. Mas, as falas indicavam, para a professora, pistas quentes para pensar o processo de alfabetização que experienciávamos com este grupo. Que sentidos revelavam suas falas, seus gestos, seus silêncios?

A docente sugeriu, então, às crianças, no acontecimento da roda, que elaborassem, com as falas, uma Mandala.

- Uma mandala, tia!? - retrucou Pérola, curiosa por saber do que se tratava.

Assim como Pérola, outras crianças ficaram instigadas, e a curiosidade em descobrir o que era uma mandala virou uma brincadeira de desvendar, de adivinhar. Desafiadas, foram pesquisar: o que é uma mandala? Perguntaram às mães, pais, avós, irmãs e irmãos; consultaram a internet. Levaram, praticamente, dois dias para que desvelassem o mistério...

- E, por que uma mandala, tia? - perguntou Ericka.

Durante as rodas de conversa, as crianças logo perceberam que outras atividades realizadas em sala, cotidianamente, se associavam à ideia e à proposta da mandala. Ressaltaram: o formato circular da roda de conversa, as ideias, informações e aprendizados que habitam a sala de aula, as discussões que vêm e vão e retornam muitas vezes, as várias e diferentes falas e pensamentos, as brincadeiras, os desejos... E, Beatriz, em uma fala-síntese, nos disse, admirada: 


\section{- Tia, tem a ver com o que fazemos todo dia!}

Sim, a mandala é mais do que um desenho. A cada dia, em roda, as ideias em conversa iam tecendo a mandala. Das palavras ditas, algumas foram insistindo em permanecer: brincar, falar, pensar, estudar, viver, imaginar, amizade, grupo. Palavras indicativas, fortes no coletivo, diferentes em seus sentidos para cada umx. Uma artesania coletiva gestava-se. As ideias, iguais e diferentes, ampliavam-se na singularidade de cada criança artesã. Nesse tecer de ideias, um exercício que envolvia gestos de escuta, de espera, de atenção ao que era vivido; gestos de ajuda e de amizade; conflitos, ações de colaboração, interação; curiosidade na escrita dos pensamentos:

- Como se escreve...? Com qual letra? Essa letra se repete?

- Ih! É a letra do meu nome! Esta é a letra do nome do meu pai!

- Mas, tia, o som é do “z”, não é? Escreve com o "s”?

- Nossa, quanta letra junta! Tia, tem de fazer a curva...

Nesse movimento de produção, interação, perguntas, conversas, a mandala ia, aos poucos, ganhando vida. O processo de pensar e usar a linguagem escrita acontecia sem palavras-chaves e sem "famílias silábicas; sem a dicotomia entre letras "fáceis" ou "difíceis"; sem cópia, repetição e memorização através de exercícios mecânicos e, por conseguinte, sem sentido. A linguagem escrita ia sendo, tal como a linguagem oral, experimentada, experienciada, vivenciada, mas não por obrigação ou para cumprir o dever, mas para construir algo da turma, prenhe de afeto, afetividade, sentido. As letras e palavras, mais do que transcrever sons, transcreviam a autoria de fala de cada criança, autoria que marcava-se, agora, no papel. Escrevia-se na escola e não para a escola, como nos provoca a pensar Geraldi (2010).

(...) não se trata evidentemente de confinar a questão educacional à linguagem, mas trata-se da necessidade de pensá-la à luz da linguagem. (...) não se trata de linguagem vista como repertório, pronto e acabado, de palavras conhecidas ou a conhecer e de um conjunto de regras a automatizar; nem da linguagem como tradução de pensamentos que lhe seriam prévios; menos ainda da linguagem como um conjunto de figuras de enfeite retórico; e muito menos ainda da linguagem vista como "forma correta", ortográfica, de palavras ou sentenças. (...) Trata-se de um deslocamento para. É eleição de um outro lugar. (Idem, p. 34)

O desejo em registar, por escrito, o que era pensado, trocado, negociado e decidido, mobilizava o grupo. 


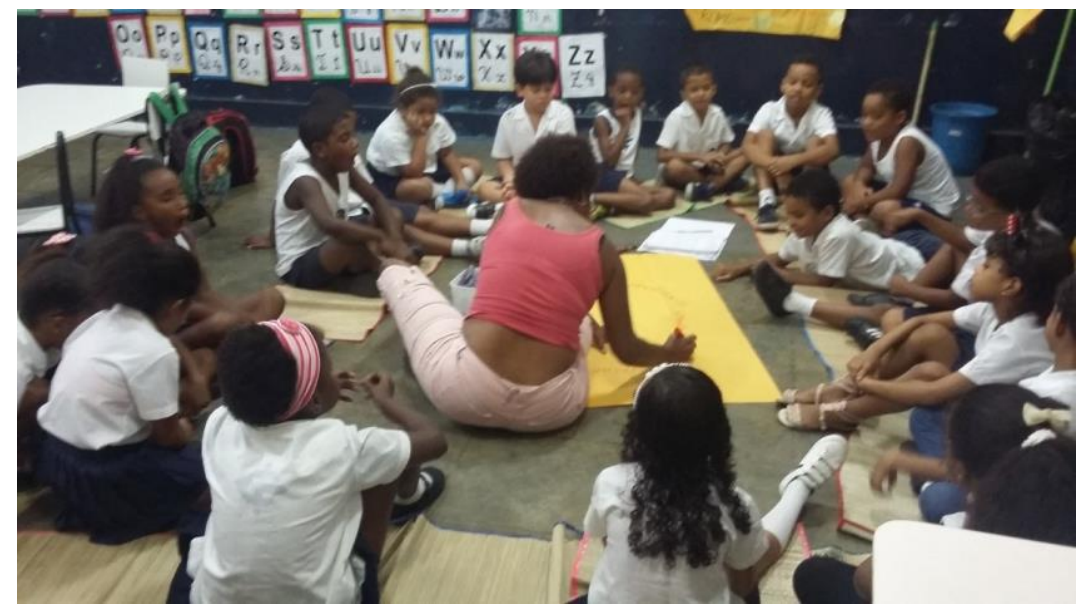

Figura 1: escrita da mandala no papel. (Fonte: arquivo da pesquisa)

Naquele momento, poucas eram as crianças que conseguiam ler ou escrever sem ajuda; a professora, por isso, era a escriba, a referência e quem informava e chamava atenção para como escrever. Ia perguntando, incitando, convidando a pensar, por mais que "pensar canse", como falara Gabriel, na roda de conversa. Mas pensar com x outrx é diferente de pensar sozinhx. A ajuda potencializa, como nos ensinou Vigotski (1989), os conhecimentos prospectivos, abrindo espaço para que, compartilhadamente, ampliemos e espichemos nossos "ainda não saberes" (ESTEBAN, 2003).

As hipóteses elaboradas pelas crianças no movimento de ler e de escrever, como sabem e podem, desde o primeiro dia de aula, nesta sala de aula, é o que impulsiona seus aprendizados. No gesto de escrever e no gesto de ler, o pensamento movimenta-se no próprio processo de pensar com a escritura e com a leitura. Afinal, como se aprende a ler e a escrever? Lendo e escrevendo... e com leitorxs e escritorxs experientes que possam tirar dúvidas, confirmar ou não as hipóteses elaboradas pelas crianças, dar pistas e, sobretudo, acolher as crianças, em suas diferenças, com suas certezas e incertezas, seus medos e coragens, suas curiosidades, suas invencionices. X professxr alfabetizadxr pode e deve ser essx leitxr e escritxr experiente atentx à complexidade e singularidade constitutivas desse processo de aprendizagemensino. Umx professxr que não abra mão de pensar, de tomar decisões, de criar e de pesquisar a própria prática alfabetizadora. Que socialize e possa compartilhar com seus pares e grupos suas dúvidas, incertezas, descobertas, aprendizados diários no exercício cotidiano de ir tornando-se umx melhor professxr no exercício da docência (SCHÖN, 1992).

A necessidade de ter contato com a linguagem escrita, de experienciar situações de leitura e de escrita mesmo sem saber ler e escrever é um aprendizado resultante de nossas trocas, leituras e estudos e de, sobretudo, nosso exercício de escuta ao que as crianças nos sinalizam e indicam, com 
suas produções, silêncios e vozes. Isto porque, "para alfabetizar é preciso ter acesso à língua escrita (tanto como para aprender a falar é necessário ter acesso à língua oral) e é isso que está ausente nas famosas cartilhas ou manuais "para aprender a ler" (FERREIRO, 2011, p. 35. Grifo no original).

Ter como referência uma concepção de alfabetização como construção coletiva, diferentemente do que levam a pensar as cartilhas e os métodos de alfabetização, exige compreender o processo de aprendizagemensino como "um sistema vivo que pressupõe um diálogo dos aprendizes com o seu futuro e não um diálogo com o passado para se apropriar da herança cultural de uma sociedade" (GERALDI; FICHTNER; BENITES, 2006, 23). Sendo assim, o que já sabem as crianças, mas, sobretudo, o que ainda não sabem, precisa ser o foco da atenção docente.

Sabemos que a sensibilidade para ouvir as crianças é imprescindível para pensar a alfabetização a partir de suas falas, desejos, anseios. As falas, para a professora da turma, são falaspistas para trilhar com as crianças uma alfabetização artesã, pois os pensamentos estão enredados pela mandala. Pensamentos que se abrem e se abriam, na criação da mandala, a outros pensares e a nós mesmxs. Esse processo interroga, sempre, a própria prática alfabetizadora, a cada ano, a cada turma. Singularidade e complexidade, ao invés de apenas realizar os passos ou etapas de um determinado método de alfabetização. A compreensão de que essas falas-pistas podiam ser princípios de convivência e de aprendizagens no processo de aprender a ler e a escrever, para este grupo, tornou-se forte no movimento mesmo de vivenciar esse processo de construção com as crianças.

Com a professora assumindo, temporariamente, o lugar de escriba, e as crianças participando do processo informando, perguntando, destacando que letra usar ou não usar, a mandala, ou a primeira versão dela, ficou pronta: 


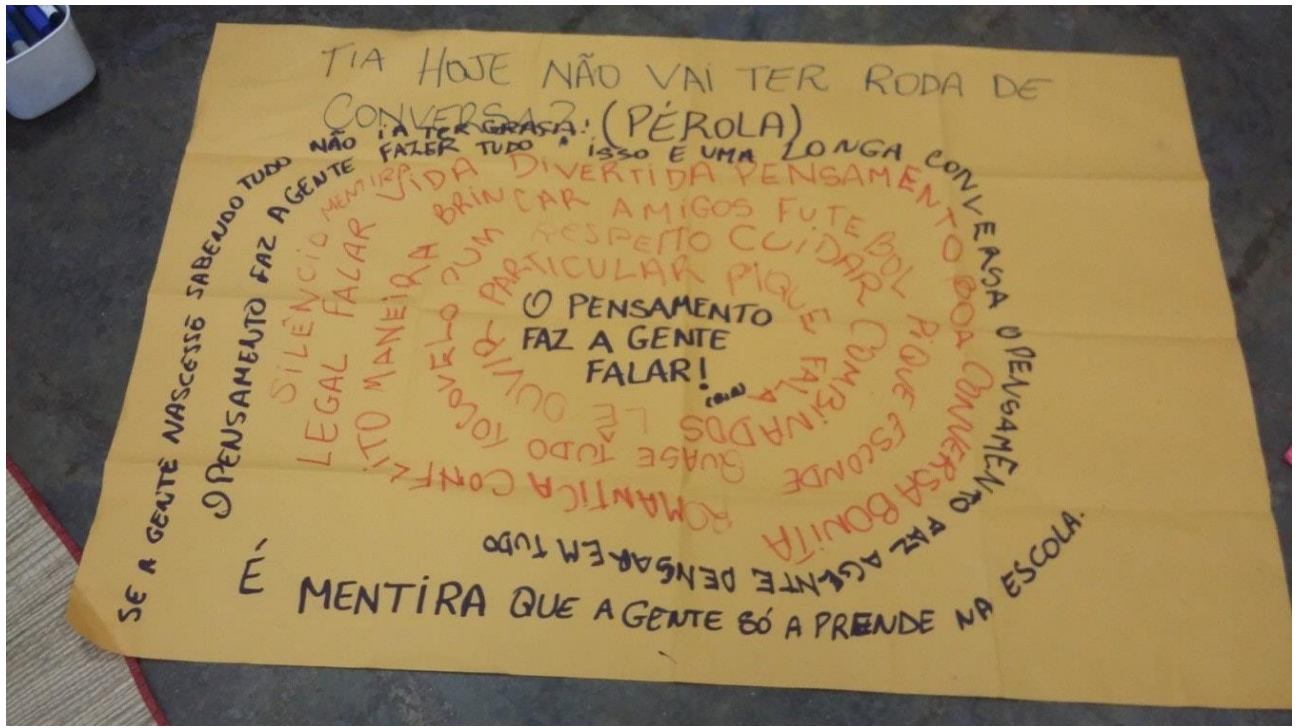

Figura 2: Mandala no papel pardo. (Fonte: arquivo da pesquisa)

As crianças, como sujeitxs de seu próprio processo de aprendizagem, reconheciam-se na singularidade do desenho, no traçado, único e irrepetível, daquela mandala, que agora ganharia, como desdobramento da atividade inicial, forma no pano. As canetas coloridas, o lápis cera, a cola colorida, a areia... Materiais outros em um suporte diferente do papel que demandavam movimentos e sensações outras. No traçado da escrita das palavras, a leitura que cada umx faz de si mesmx, como lê e interpreta o mundo marcava presença e isto faz, para a prática alfabetizadora, toda a diferença! Repetimos: uma alfabetização artesã tecida com as crianças, no dia a dia da sala de aula, que aposta na possibilidade de tornar-se uma experiência, para as crianças e para as pessoas adultas que com elxs (com)partilham esse processo. Aprender a ler e a escrever para se inscrever no mundo de modos outros: mudanças, deslocamentos, rupturas, criações, invenções...

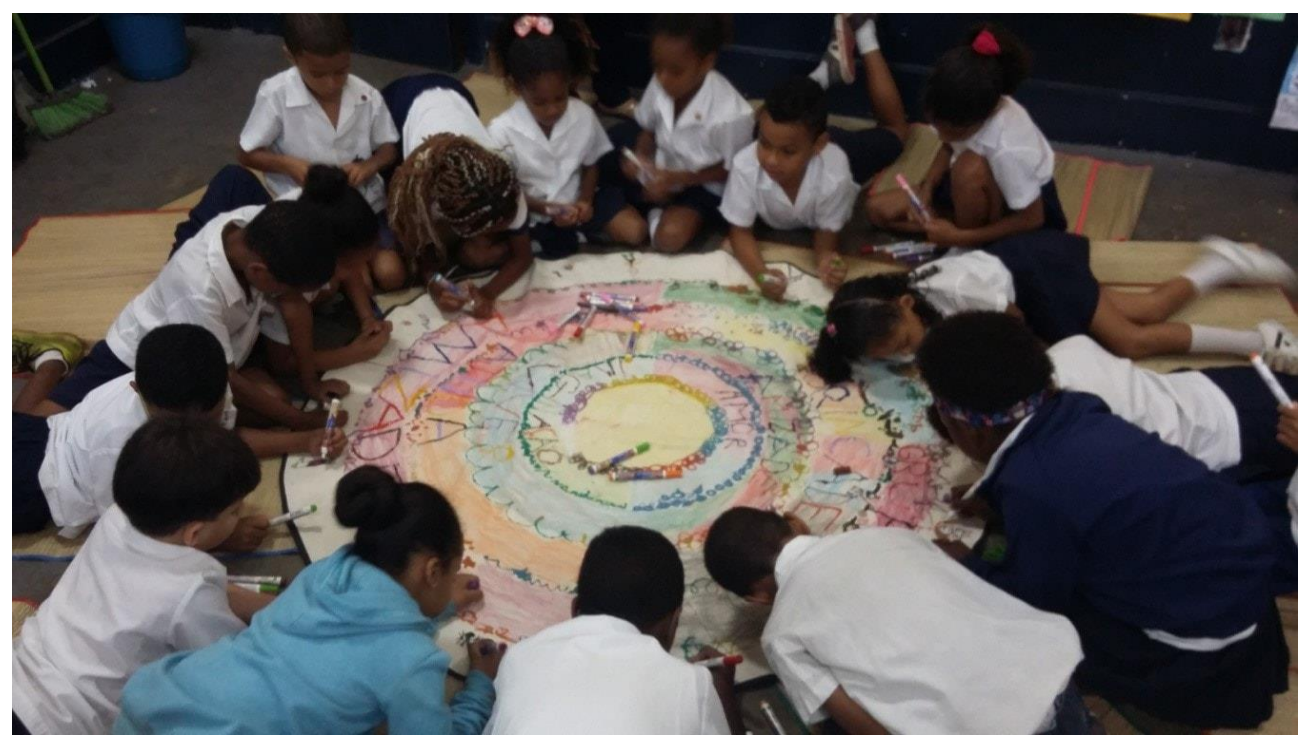


Figura 3: Produção da mandala no pano. (Fonte: arquivo da pesquisa)

O processo de produção da mandala, como tantas outras experiências que poderíamos evocar aqui, nos convida a pensar sobre o currículo na alfabetização. Não se trata de ensinar letras, sílabas e palavras-chave. Não se trata, como ainda é hegemonicamente pensado, de um processo solitário que evita o erro e preza pelo individualismo e pela competição, focando na aprendizagemensino da língua como se se tratasse da aquisição de um mero código fixo. Estamos falando de um processo discursivo (SMOLKA, 2000), não apenas de aquisição de uma técnica, mas de apropriação de um sistema vivo.

Ao pensarmos em um currículo na alfabetização, não estamos nos referindo a um rol de conhecimentos a serem trabalhados ou conteúdos a serem ministrados. Apostamos na ideia de um “currículo como criação cotidiana" (OLIVEIRA, 2013) na medida em que ele se aproxima ou torna possível o exercício de escuta, de atenção para as relações diárias, para os desejos e curiosidades, para processos de criação e invenção:

Nos currículos das escolas, os praticantespensantes das escolas criam currículo únicos, inéditos, "irrepetíveis", produzem alternativas aos problemas e dificuldades que enfrentam, ao que não lhes agrada ou contempla, ao já existente e ao já sabido, contrariamente ao que supõem as perspectivas hegemônicas de compreensão dos currículos escolares que os compreendem como um eterno reproduzir daquilo que foi previsto e prescrito. (OLIVEIRA, 2013, p. 59, grifo no original).

Trata-se de um mudança estético-político-metodológica. Trata-se, como já nos disse Wanderley Geraldi (2010), de um deslocamento para. É eleição de um outro lugar. A alfabetização, enquanto processo discursivo, nos provoca a pensá-la para além dos limites do que vem sendo reavivado hegemonicamente nas escolas e reforçado por políticas públicas que têm investido em materiais nos quais os velhos métodos são revestidos com novas roupagens, mas estão lá, com a mesma base epistemológica que vê na cópia, na repetição e na memorização as dimensões fundantes da aprendizagem da leitura e da escrita. Essas ideias são reforçadas por exames externos de âmbito nacional, estadual ou municipal, como Provinha Brasil e Provinha Rio, por exemplo, subsidiadas pelas políticas públicas implementadas que determinam a idade de oito anos como limite para que todas as crianças estejam alfabetizadas.

Diferentemente, apostar na alfabetização como prática discursiva demanda investir na ideia de que, através do ato de ler, escrever e dizer nossa palavra, apropriamo-nos do mundo, reescrevemos nossas próprias histórias na leitura e na escrita, porque nela entramos, fazemos 
ranhuras, preenchemos seus vazios (ainda que produzidos por nós) com nossos significados. Lemos com todos os sentidos. Lemos a palavramundo freireana, indagamos nossos próprios modos de ver e compreender esse mundo onde vivemos e vamos, cada vez mais, nos dando conta de que ele é, também, produção humana.

Assim, trata-se de aprenderensinar a ler e a escrever lendo e escrevendo desde o início, mesmo sem se saber ler e escrever. Ler e escrever com ajuda. Ler e escrever sem ajuda. Ler e escrever sozinho. Ler e escrever com x(s) outrx(s). Modos onde a presença dx outrx se faz sempre presente, fisicamente presente ou presente na ausência, porque a presença dx outrx é constitutiva nesse processo, sempre complexo, de conhecer e aprender, de aprenderensinar a ler e a escrever...

Ler o que se deseja, sobre o que se pensa e o que desperta a curiosidade. Escrever sobre o que atravessa, o que faz sentido e provoca a pensar, a dizer a palavra própria. Um "currículo praticado" (OLIVEIRA, 2013), sim; um currículo vivido e criado! Um currículo tecido e gestado no cotidiano, nas rodas de conversa, no intercâmbio de experiências e desejos; conflitos e afetos. Neste contexto, entram na escola, na sala de aula, os textos que circulam na vida, no mundo. Lê-se textos que se incorporam aos movimentos, projetos e ações vividas pelas crianças. Ler e escrever, nessa perspectiva, afastam-se do ler e escrever para fazer dever!

$$
* * *
$$

Após alguns dias, a mandala de pano estava praticamente finalizada. É importante destacar que, em sua composição, cada desenho, cada escrita, teve a sua história. Cada cor, seu significado. A textura da areia e da cola colorida trouxeram a subjetividade que a infinitude do pensar possuí. Desenhos, formas, falas, cores, sentimentos, ideias, muitas ideias, muitos pensamentos que afirmavam uma maneira outra de alfabetização e com ela, inspirados, em Walter Kohan, a partir de nossas conversas, uma maneira outra de viver. Mas, faltava, ainda, escolher um nome para a mandala. Como disse Beatriz, em uma das rodas:

\section{- Não pode ser qualquer nome!}

Enquanto o grupo pensava um nome para a mandala, a professora, ao ler as palavras poeticamente registradas, refletia sobre as ideias e os princípios que revelavam. Pensava, ainda, no desafio que vivíamos, crianças e adultxs, ao praticá-los cotidianamente. A lembrança do que 
aprendêramos com Hampaté Bâ (2010) - "as pessoas são feitas de palavras e, exatamente por isso, são criadoras" - reportou-a a um conceito filosófico africano: Ubuntu!

Ubuntu é filosofia africana que exprime um conceito humanista, um modo de viver que une a singularidade e a coletividade. O pensamento Ubuntu se enlaça sobre a ideia da comunidade, da solidariedade e do diálogo. O sentido humanista do Ubuntu está diretamente ligado ao outro: "Eu sou porque nós somos".

A singularidade de cada criança da turma está ligada ax outrx que com ela compartilha, conversa, pensa, brinca, aprende, ensina. Somos um coletivo e somos singulares. Isso é perseguido e experienciado no cotidiano desta sala de aula. Mas, não é uma aposta tranquila de realizar, pois a lógica individualista, competitiva, branca, eurocêntrica e racista, infelizmente ainda fortemente presente em nossa sociedade e, portanto, também na escola, provoca, com frequência, situações de opressão, exclusão, colonialidade e, sobretudo, o apagamento da história e culturas africanas e afrobrasileiras nos currículos.

Conflitos, conversas, escuta, fala, escrita, leitura... um processo que passa a interrogar nossos modos aprendidos de ser professxr, de ser professxr alfabetizadxr, de ensinar, de aprender, de compreender(se). A professora alfabetizadora da turma, uma mulher assumidamente negra, vem apostando, nos últimos anos e cada vez com mais intensidade, em uma educação antirracista. Uma educação que visibiliza o que historicamente tem sido invisibilizado - heranças negras na cultura brasileira. Preocupa-se com o defendido por Wanderson Flor do Nascimento:

(...) é preciso abandonar os fardos que nos levam a vernos a nós mesmos, enquanto herdeiras/os do continente negro, como impotentes, desconstruindo, à nossa maneira, as histórias que nos foram contadas sobre nós mesmos e nossas limitações ou ausências de potências intelectuais. É preciso desacreditar nas determinações ontológicas (históricas ou naturalizadas) acerca das impossibilidades do nosso pensar. (NASCIMENTO, 2016, p. 207).

Alfabetizar lendo, escrevendo e falando. Nas rodas de conversa realizadas diariamente, a oralidade é a centralidade. Conhecimentos e desconhecimentos circulam interrogando hierarquias e classificações, como "o mais ou menos inteligente", "o que sabe mais" ou o que tem "dificuldades para aprender”. As diferenças, antes identificadas para comparar e hierarquizar, agora nos revelam modos singulares de pensar, agir, aprender, ensinar, ler e escrever das crianças. Perguntarmos, com insistência: como lidar com as diferenças, constitutivas de toda sala de aula, porque constitutivas da vida cotidiana e dxs sujeitxs, fugindo, como nos convida Skliar (2007, p.108, grifo nosso), de um "processo de diferencialismo que consiste em separar, em distinguir, dentro da diferença, algumas 
marcas diferentes e de fazê-lo sempre a partir de uma conotação pejorativa, negativa, subalterna"? Tal questionamento nos provoca interrogações e desaprendizagens e ainda exige, de nós, como ressaltou com veemência Regina Leite Garcia (2015), nas discussões realizadas sobre formação docente, currículo e alfabetização, a articulação necessária e sempre permanente entre práticateoriaprática.

Assim, modos solidários e colaborativos de aprenderensinar vão ganhando sentido, vão se aconchegando nas interações vividas no dia-a-dia da sala de aula. Todas as crianças sabem e ainda não sabem muitas coisas; conhecem e desconhecem... como nós adultxs, que com elas compartilhamos esse processo de aprender-ensinar-alfabetizar. Desde ubuntu, destaca novamente Wanderson Flor do Nascimento (2010): "não se prioriza nenhum tipo de competição, mas de colaboração solidária". A professora sabe disso e, não por acaso, sugere e conversa com as crianças sobre a palavra ubuntu. Daí a escolha do nome da mandala com as crianças em uma Roda de Conversa, com a participação de estudantes e professorxs vinculadxs ao PIBID: Mandala Ubuntu.

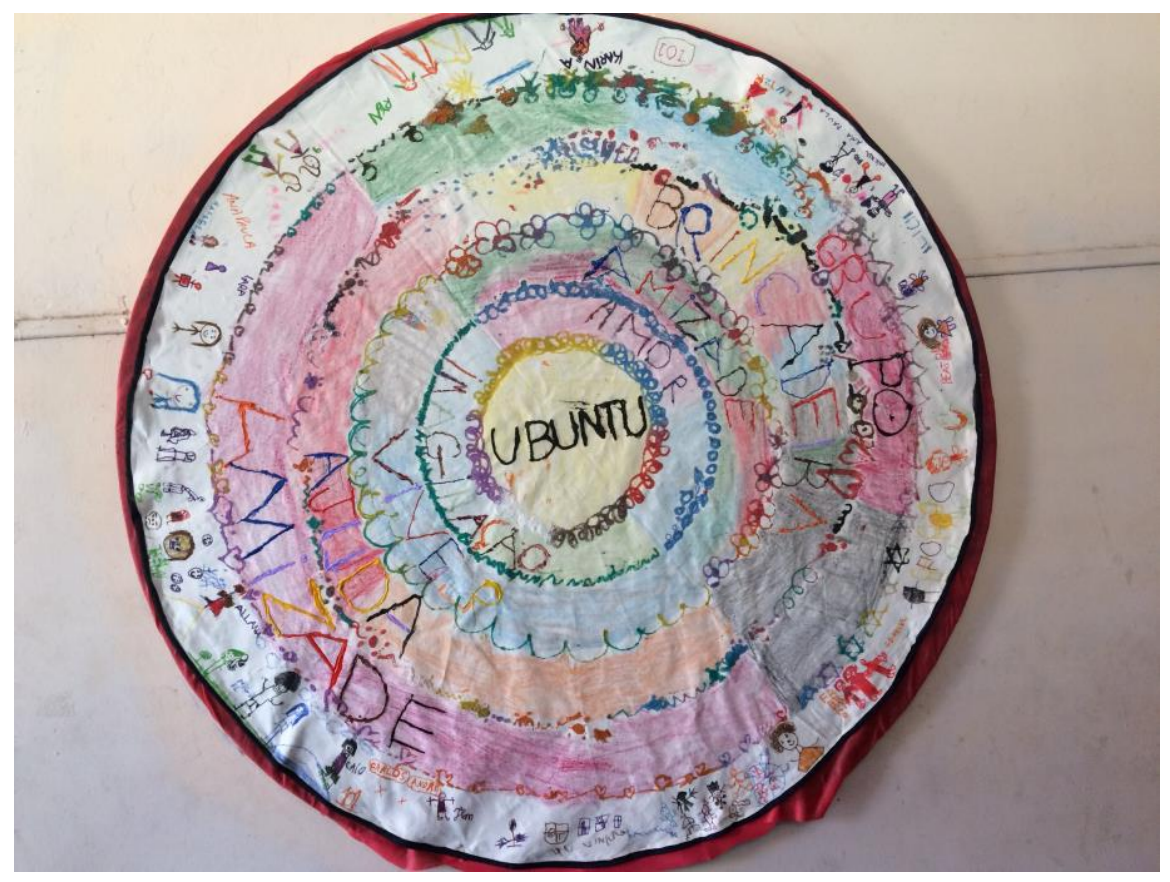

Figura 4: Mandala Ubuntu

No diálogo entre as culturas afro-brasileiras e africanas, uma produção tecida e saboreada por cada criança e estudante do PIBID que, no (com)partilhar esse processo alfabetizador, marcadamente ético, estético e político, vivem modos outros de ser professxr de crianças, professorxs alfabetizadorxs comprometidxs com o convite insistente de Walter Mignolo (2010, p. 09) de que é necessário e urgente “descolonizar los conocimientos y el ser”... 


\section{PALAVRAS INCONCLUSIVAS... PARA SEGUIR PENSANDO COM AS CRIANÇAS}

A professora, o grupo do PIBID, com os encontros de filosofia e a Mandala acompanharam a turma para o $2^{\circ}$ ano de escolaridade. Afinal, como aprender a ser professxr de crianças, professxr alfabetizadxr a não ser por meio das relações que com elas vivemos? Como praticar uma educação, um currículo e uma alfabetização intercultural sem interrogar a legitimidade da existência de uma cultura dominante que aceita, tolera ou apenas "reconhece" a existência de outras culturas?

Poucas, muito poucas, são as crianças desta turma que ainda não estão alfabetizadas. Estão, ressaltamos, em um processo intenso de aprendizagens porque movidas pelo desejo, curiosidade, pelas leituras e escritas que já realizam cotidianamente, na escola e fora dela. Crianças que se reconhecem em suas potencialidades, direitos e responsabilidades. Não por acaso, quando a professora, na Roda de Conversa, falou sobre a apresentação que faria no Seminário Internacional As Redes de Conhecimentos e as Tecnologias, na UERJ, sobre a prática alfabetizadora vivida com a turma, uma menina, com um olhar atento, pergunta:

- Tia, a mandala não é nossa? Não é da turma?

- Sim, é da turma. De todxs nós! - responde a professora.

- Então, por que você vai levar para a UERJ sem nos pedir?

Uma fala que emudece, dá a pensar e a apostar nessa relação em que as crianças, cada vez mais, se assumem enquanto sujeitxs, de conhecimento, cultura e saber! Sujeitxs que podem decidir sobre o que vivem, o que fazem. Sujeitxs hoje e não amanhã!

É importante dizer que conversamos com as crianças, com xs pais, mães e responsáveis sobre os textos escritos e socializados, nos congressos, encontros e publicações realizadas. Uma cópia dos textos e circulam entre as crianças e entre xs adultxs - sujeitxs participantes da pesquisaformação compartilhada. Nilda Alves (2013) lembra-nos, insistentemente, que esses processos formativos, de aprendizagemensino e curriculares ocorrem dentrofora das escolas; são tecidos em redes de conhecimentos e significações que "formamos e que nos formam" (p. 35). 
Processos complexos que exigem abertura para vivermos o "aleatório singular do acontecimento" (FOUCAULT, 1999).

Para a professora, uma informação importante e talvez rápida, sobre o trabalho a apresentar. Mas, a pergunta feita pela criança irrompe o vivido, o próprio tempo, em sua intensidade e linearidade; irrompe sentidos que circulavam provocando outros e novos sentidos e ações. A conversa se estica, se desdobra e foge dos limites antes imaginados. As crianças votam e decidem o que fazer. A Mandala UBUNTU acompanha a professora em sua apresentação, mas, junto com ela, vai uma carta escrita, coletivamente, pela turma, pois as crianças queriam dizer de si e de seus aprendizados para as pessoas que estariam ouvindo a professora, na UERJ.

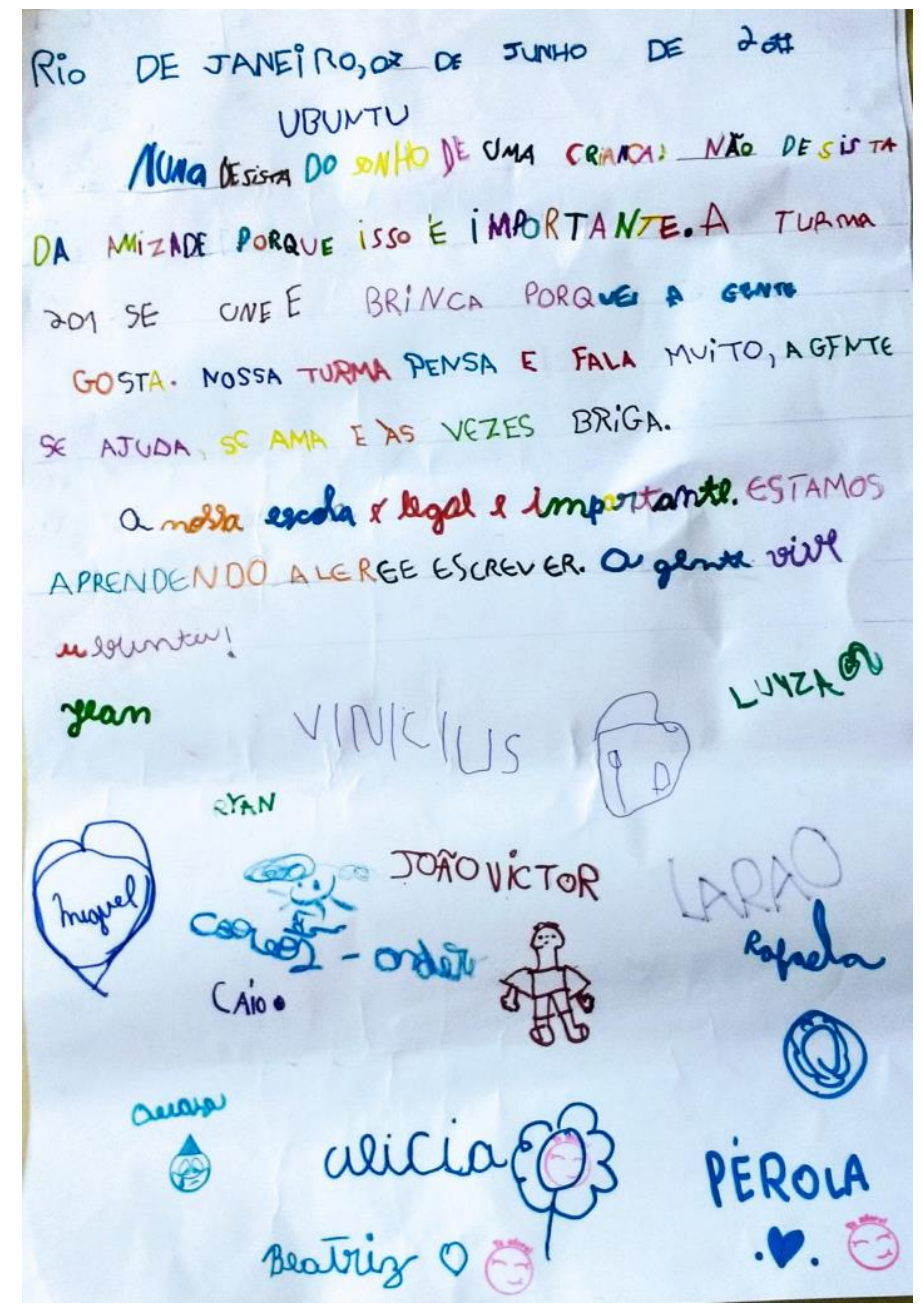

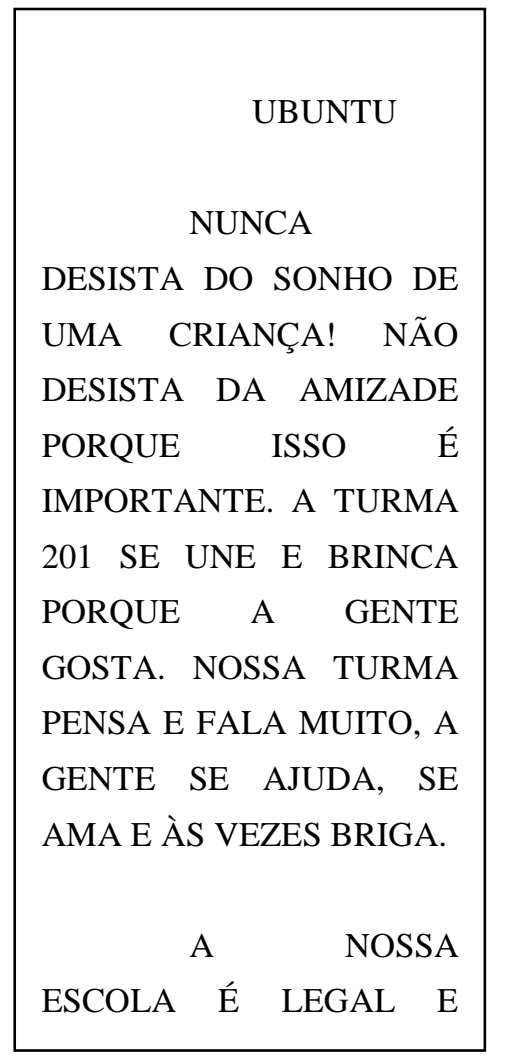

Figura 5: carta enviada para a UERJ/ Seminário Redes

Estar com as crianças e ouvi-las em seus desejos, curiosidades e provocações têm nos feito pensar. Formamos e nos formamos nesses encontros... Se estamos dispostxs a abandonar o lugar de 
saber, da certeza e abrirmo-nos à experiência da desaprendizagem, do inacabamento, então as crianças podem nos dar pistas sobre nosso fazer pedagógico, sobre nossa própria prática.

Por que não formar-se professxr no encontro com as crianças? Por que não formar-se professxr nos processos vividos, muitas vezes despercebidos e não valorados, de criaçãa cotidiana de currículos?

Paulo Freire (2008) lembra-nos que "a leitura da palavra não é apenas precedida pela leitura do mundo, mas por uma certa forma de escrevê-lo ou de reescrevê-lo”. Afinal, a quem interessa que a aprendizagem da linguagem escrita tenha como referência atos mecânicos de reconhecimento? Por que não uma alfabetização centrada na autoria, criação e na potência do pensamento?

\section{REFERÊNCIAS:}

ALVES, N. Currículos e pesquisas com os cotidianos. In: FERRAÇO, C. E.; CARVALHO, J. M. (orgs). Currículos, pesquisas, conhecimentos e producão de subjetividades. Petrópolis, RJ: DP et Alii; Vitória, Es: Nupec/Ufes, 2013.

ESTEBAN, T.; ZACCUR, E. (orgs.) Professora-pesquisadora: uma práxis em construção. Rio de janeiro: DP\&A, 2002.

ESTEBAN, M. T. O que sabe quem erra? Rio de Janeiro: DP\&A, 2003.

FERREIRO, E.; TEBEROSKY, A. Psicogênese da língua escrita. Porto Alegre: Artes Médicas, 1985.

FERREIRO, E. Com todas as letras. 16 ${ }^{\mathrm{a}}$ ed. São Paulo: Cortez, 2011.

FOUCAULT, M. Nietzsche, a genealogia e a história. In: FOUCAULT, M. Microfísica do poder. 14 ${ }^{\mathrm{a}}$ ed. Rio de Janeiro: Graal, 1999

FREIRE, P. A importância do ato de ler: em três artigos que se completam. 49ª ed. São Paulo: Cortez, 2008.

GARCIA, R. L. (org.). A formacão da professora alfabetizadora: reflexões sobre a prática. $6^{\text {a }}$ ed. São Paulo: Cortez, 2015 .

; ALVES, N. Conversa sobre pesquisa. In: ESTEBAN, T.; ZACCUR, E. (orgs.) Professora-pesquisadora: uma práxis em construção. Rio de janeiro: DP\&A, 2002.

Sobre formação de professores e professoras: questões curriculares. In: LIBÂNEO, J. C.; Alves, N. (orgs). Temas de pedagogia: diálogos entre didática e currículo. São Paulo: Cortez, 2012.

GERALDI, W. J. A aula como acontecimento. São Carlos: Pedro \& João Editores, 2010.

GERAlDI, J. W.; FICHTNER, B.; BENITES, M. Transgressões Convergentes: Vygotsky, Bakhtin, Bateson. Campinas: Mercado das Letras, 2006.

HAMPATÊ BÂ, A. A tradição viva. In: Ki-ZERBO, J. (ed.). História Geral da África I. Metodologias e Pré-história da África. Brasília: Unesco, 2010.

KOHAN, W.; OLARIETA, B. F. (orgs.). A escola pública aposta no pensamento. Belo Horizonte: Autêntica, 2012. 
MORTATTI, M. R. L. Os sentidos da alfabetização: São Paulo 1876/ 1994. São Paulo: UNESP, 2000.

MIGNOLO, W. Desobediencia epistémica: retórica de la modernidad, lógica de la colonialidad y gramática de la descolonialidad. Buenos Aires: Del Signo, 2010.

NASCIMENTO, W. F. Tecendo mundos entre uma educação antirracista e filosofias afro-diaspóricas da educação. In: KOHAN, W.; LOPES, S.; Martins, F. O ato de educar em uma língua ainda por ser escrita. Rio de Janeiro: NEFI, 2016.

OLIVEIRA, I. B. Currículos e pesquisas com os cotidianos; o caráter emancipatório dos currículos pensadospraticados pelos praticantespensantes dos cotidianos das escolas. In: FERRAÇO, C. E.; CARVALHO, J. M. (orgs). Currículos, pesquisas, conhecimentos e producão de subjetividades. Petrópolis, RJ: DP et Alii; Vitória, Es: Nupec/Ufes, 2013.

; SGARBI, P. Estudos do cotidiano \& Educação. Belo Horizonte: Autêntica, 2008.

PÉREZ GÓMEZ, A. A cultura escolar na sociedade neoliberal. Porto Alegre: Artmed, 2001.

SCHÖN, D. Formar professores como profissionais reflexivos. In: NÓVOA, A. (coord.) Os professores e a sua formação. $2^{\text {a }}$ ed. Lisboa: Publicações Dom Quixote, 1992.

SKLIAR, C. La educación (que es) del otro. Argumentos y desierto de argumentos pedagógicos. Buenos Aires: Centro de Publicaciones Educativas Y Material Didáctico, 2007.

SMOLKA, A. L. B. A criança na fase inicial da escrita: a alfabetização como processo discursivo. $12^{\mathrm{a}}$ ed. São Paulo: Cortez, Campinas, SP: Universidade Estadual de Campinas, 2008.

TUTU, D. Il n’y a pas d'avenir sans pardon. Paris: Albin Michel, 1999.

VYGOTSKY, L.S. A formação social da mente. São Paulo: Martins Fontes, 1989.

Abstract: The present text reflects on the process of learning and teaching to read and write with reference in the children's curiosity, questions and desire. In the movement of thinking discursive literacy, grounded in production, collective thinking and the authorship of speech and thought, this paper highlights the importance of the child as a powerful element in teacher training. In bringing experiences and events lived through a research in a public school in Rio, it underlines how challenging it is to think of literacy outside the norms of literacy methods, calling into question the curriculum and the training of professors who work in the area.

Keywords: Discrusive literacy; Teacher training with children; School everyday life

Resumen: El presente texto teje reflexiones sobre el proceso de aprender y enseñar a leer y a escribir teniendo como referencia la curiosidad, las preguntas y el deseo de los niños. En el movimiento de pensar una alfabetización discursiva, basada en la producción, en el pensar colectivamente y en la autoría de habla y pensamiento, destaca la importancia del niño como otro potente en la formación docente. Al traer experiencias y acontecimientos vividos a lo largo de una investigación en una escuela pública carioca, subraya cuán desafiante es pensar una alfabetización fuera de las normativas de los métodos alfabetizadores, poniendo en cuestión el currículo y la formación dx maestrx que allí actúa.

Palabras clave: Alfabetización discursiva; Formación docente con los niños; Cotidiano escolar. 